08,04

\title{
Димерная самоорганизация примесных ионов эрбия в синтетическом форстерите
}

\author{
(ㄱ Р.Б. Зарипов ${ }^{1}$, Л.В. Мингалиева ${ }^{1}$, В.Ф. Тарасов ${ }^{1, \uparrow, ~ Е . В . ~ Ж а р и к о в ~}{ }^{2}$, К.А. Субботинн, ${ }^{2,3}$, Д.А. Лис ${ }^{2}$ \\ ${ }^{1}$ Казанский фризико-технический институт им. Е.К. Завойского - обособленное структурное подразделение \\ Федерального исследовательского центра „Казанский научный центр Российской академии наук“, \\ Казань, Россия \\ ${ }^{2}$ Институт общей фозики им. А.М. Прохорова, \\ Москва, Россия \\ ${ }^{3}$ Российский химико-технологический университет им. Д.И. Менделеева, \\ Москва, Россия \\ 『 E-mail: tarasov@kfti.knc.ru
}

(Поступила в Редакцию 6 августа 2018 г.)

Методом электронного парамагнитного резонанса в X- и Q-диапазонах частот исследованы спектры электронного парамагнитного резонанса примесных ионов трехвалентного эрбия в монокристаллах синтетического форстерита $\left(\mathrm{Mg}_{2} \mathrm{SiO}_{4}\right)$. Установлено что ионы эрбия замещают, преимущественно, ионы магния в кристаллографической позиции М1, характеризующейся инверсионной симметрией кристаллического поля. При этом имеет место выраженный эффект димерной самоорганизации ионов эрбия в процессе роста кристаллов, выражающийся в том, что концентрация димерных ассоциатов эрбия, состоящих из двух близко расположенных ионов, связанных спин-спиновым взаимодействием, на несколько порядков превышает концентрацию димерных ассоциатов, образующихся случайно при статистическом распределении примесных ионов в кристаллической решетке форстерита. Определены направления главных магнитных осей и параметры эффективного спинового гамильтониана, описывающего магнитные характеристики примесных центров эрбия.

Настоящая работа в части синтеза образца и выявления фактической концентрации эрбия в нем методами рентгеноспектрального микроанализа и оптической абсорбционной спектроскопии осуществлялась при финансовой поддержке Российского научного фонда (грант № 18-12-00517).

DOI: $10.21883 /$ FTT.2019.02.47131.227

\section{1. Введение}

Известно, что в монокристаллах форстерита $\left(\mathrm{Mg}_{2} \mathrm{SiO}_{4}\right)$ примесные редкоземельные ионы $(\mathrm{Ln})$ замещают двухвалентные ионы магния [1-6]. При таком гетеровалентном замещении необходим специальный компенсатор избыточного катионного заряда, в роли которого выступают точечные дефекты с эффективным зарядом противоположного знака. Образование такого точечного дефекта неизбежно увеличивает внутреннюю энергию кристаллической решетки, поэтому, как правило, вхождение гетеровалентных редкоземельных примесей в кристаллы форстерита протекает с определенным трудом [7,8]. Если при этом специально не вводить в состав кристалла $\mathrm{Ln}: \mathrm{Mg}_{2} \mathrm{SiO}_{4}$ какие-либо ионы зарядовых компенсаторов (например $\mathrm{Li}^{+}$), то в роли таких компенсаторов могут служить магниевые вакансии $V_{\mathrm{Mg}}^{\prime \prime}[6]$, которые в небольших количествах всегда присутствуют в кристаллах форстерита. Здесь и далее все обозначения заряженных точечных дефектов даны по Крегеру-Винку [9]. Однако, в отличие от иона лантаноида, локализованного в магниевой позиции $\left(\mathrm{Ln}_{\mathrm{Mg}}^{\bullet}\right)$ и имеющего в ней лишь одинарный избыточный положительный заряд, вакансии $\mathrm{V}_{\mathrm{Mg}}^{\prime \prime}$ заря- жены двукратно и, таким образом, каждая из них служит для зарядовой компенсации сразу двух ионов $\mathrm{Ln}_{\mathrm{Mg}}^{\bullet}$.

В работе [5] методом структурного компьютерного моделирования на примере кристаллов $\mathrm{Yb}: \mathrm{Mg}_{2} \mathrm{SiO}_{4}$ было показано, что если два трехвалентных редкоземельных примесных иона с магниевой вакансией собираются в ассоциат типа $\left[\mathrm{Ln}_{\mathrm{Mg}}^{\bullet}-\mathrm{V}_{\mathrm{Mg}}^{\prime \prime}-\mathrm{Ln}_{\mathrm{Mg}}^{\bullet}\right]^{\times}$, то в этом случае зарядовая компенсация достигается при минимально возможном увеличении внутренней энергии кристаллической решетки. Следовательно, именно такой характер локализации примесных лантаноидов в кристаллах форстерита должен превалировать. Эффект подобной самоорганизации примесных трехвалентных ионов в форстерите экспериментально наблюдался для гольмия [1,2], тербия [4] и иттербия [5]. Он проявляется в наличии соответствующих димерных ассоциатов редкоземельных ионов, концентрация которых на несколько порядков превышает концентрацию этих ассоциатов, которую можно было бы ожидать при статистическом распределении примесных ионов по узлам кристаллической решетки.

В данной работе методом электронного парамагнитного резонанса (ЭПР) исследован эффект димерной самоорганизации примесных ионов эрбия в синтетическом форстерите. 
Ион трехвалентного эрбия имеет электронную конфигурацию $4 f^{11}$, основной мультиплет ${ }^{4} \mathrm{I}_{15 / 2}$ и $g$-фактор Ланде $g_{L}=6 / 5$. Эрбий имеет 6 стабильных изотопов, один из которых $\left({ }^{167} \mathrm{Er}\right)$ с естественной распространенностью $22.87 \%$ имеет ненулевой ядерный спин $I=7 / 2$. Поэтому спектр ЭПР иона эрбия должен состоять из интенсивной центральной лини, принадлежащей четным изотопам, и восьми линий, принадлежащих изотопу ${ }^{167} \mathrm{Er}$, с относительной интенсивностью каждой линии 0.037 .

В кристаллическом поле ромбической или более низкой симметрии низколежащие электронные уровни основного мультиплета эрбия представлены крамерсовыми дублетами, между уровнями которых можно наблюдать резонансные переходы в подходящем магнитном поле. Результаты исследования примесных ионов эрбия в различных диэлектрических и полупроводниковых кристаллах методом ЭПР приведены в обзоре [10].

\section{2. Эксперимент}

Форстерит, легированный эрбием, выращивался методом Чохральского из расплава. Выращивание проводилось из иридиевого тигля в атмосфере азота на монокристаллическую $\mathrm{Mg}_{2} \mathrm{SiO}_{4}$ затравку, вырезанную вдоль оси $a$ (здесь и далее обозначения кристаллографических осей соответствуют установке Pbnm). Скорость вытягивания на номинальной стадии роста составляла $1 \mathrm{~mm} / \mathrm{h}$, скорость вращения - $6 \mathrm{rot} / \mathrm{min}$. В качестве шихты использовались реактивы $\mathrm{MgO}, \mathrm{SiO}_{2}$ и $\mathrm{Er}_{2} \mathrm{O}_{3}$, все реактивы имели концентрацию „ОС-Ч“. Было выращено два образца, один — „рабочий“, на котором и проводились ЭПР-исследования, а также „контрольный“, предназначенный для более точного контроля фактической концентрации легирующей примеси в образцах. Концентрация ионов $\mathrm{Er}^{3+}$, вводившихся в расплав, составляла 6 at.\% для „рабочего“ образца и 13 at.\% для „контрольного“. При этом содержание $\mathrm{MgO}$ и $\mathrm{SiO}_{2}$ в навесках рассчитывалось из мольного соотношения $2: 1$ (что соответствует стехиометрии форстерита), а $\mathrm{Er}_{2} \mathrm{O}_{3}$ добавлялся сверх этой стехиометрии. Навески тщательно перемешивались, прессовались в таблетки и прокаливались перед загрузкой в тигель.

Выращенные образцы были прозрачны и имели бледно-розовую окраску, характерную для ионов эрбия. Ориентация образцов относительно кристаллографических осей в первом приближении задавалась ориентацией затравки и зачатками естественной огранки, затем ориентация уточнялась методами рентгеновской дифракции. Для определения концентрации эрбия в кристаллах вначале методом рентгеноспектрального микроанализа была измерена его концентрация в „контрольном“ образце, оказавшаяся равной $0.084 \pm 0.002$ at.\% по отношению к магнию. Затем на обоих образцах были измерены спектры оптического поглощения в видимой области спектра, где, как известно, эрбий имеет несколько полос поглощения весьма высокой удельной интенсивности.
Было выявлено в частности, что пиковое сечение поглощения полосы перехода ${ }^{4} \mathrm{I}_{15 / 2} \rightarrow{ }^{4} \mathrm{G}_{11 / 2}$ ионов эрбия в форстерите на длине волны $\lambda=376 \mathrm{~nm}$ составляет $2.8 \cdot 10^{-20} \mathrm{~cm}^{2}$, а для полосы перехода ${ }^{4} \mathrm{I}_{15 / 2} \rightarrow^{2} \mathrm{H}_{11 / 2}$ $(\lambda=521 \mathrm{~nm})$ эта величина составляет $2.1 \cdot 10^{-20} \mathrm{~cm}^{2}$. Это позволило по спектру поглощения „рабочего“ образца рассчитать фактическую концентрацию эрбия в нем, составившую $0.025 \pm 0.001$ at.\% по отношению к магнию. Иными словами,формулу кристалла можно записать как $\mathrm{Mg}_{1.9995} \mathrm{Er}_{0.0005} \mathrm{SiO}_{4}$.

Изучение структуры и магнитных характеристик парамагнитных центров, образованных примесными ионами $\mathrm{Er}^{3+}$ в синтетическом форстерите, проводилось в $\mathrm{X}$ - и Q-диапазонах при температурах 5-100 K стационарным методом ЭПР с модуляцией магнитного поля на частоте $100 \mathrm{kHz}$. В Х-диапазоне использовался спектрометр EMX Plus с объемным металлическим резонатором ER 4122 SHQ. B Q-диапазоне использовался спектрометр ELEXSYS E580 с цилиндрическим диэлектрическим резонатором ER 5102 D2.

\section{3. Результаты и обсуждение}

В структуре форстерита имеются 2 кристаллографически различных типа кислородных октаэдров, внутри которых находятся ионы магния. Обычно эти позиции ионов $\mathrm{Mg}^{2+}$ обозначаются М1 и М2. В единичную ячейку кристалла входят 4 структурно-эквивалентных иона $\mathrm{Mg}^{2+}$ в каждой из позиций. Кристаллическое поле в позиции М1 имеет триклинную симметрию с точечной группой $C_{i}$, и для произвольной ориентации магнитного поля все 4 иона в позициях М1 являются магнитно неэквивалентными. Если магнитное поле ориентировано в плоскостях, перпендикулярных кристаллографическим осям, ионы, занимающие позиции М1, попарно магнитно эквивалентны. Кислородное окружение $\mathrm{Mg}^{2+}$ в позиции М2 характеризуется моноклинной симметрией с точечной группой симметрии $C_{s}$ и имеет зеркальную плоскость симметрии, перпендикулярную оси $c$. Зеркальная симметрия требует, чтобы главные магнитные оси парамагнитного иона в этой позиции лежали в плоскости $(a b)$ или совпадали с кристаллографической осью $c$.

Для произвольной ориентации магнитного поля относительно кристаллографических осей имеются два магнитно-неэквивалентных иона в позиции, а в случае, когда магнитное поле лежит в плоскости $а с$ или $b c$, все ионы в позиции М2 становятся магнитноэквивалентными. Измерение ориентационных спектров ЭПР позволяет однозначно определить локализацию примесного иона в кристаллической решетке.

На рис. 1 приведены спектры ЭПР, записанные при различной ориентации внешнего магнитного поля в плоскости $(a b)$. Иону $\mathrm{Er}^{3+}$ принадлежат две группы резонансных переходов, обозначенные $\mathrm{Er}$, состоящие из трех линий каждая. При ориентации магнитного поля вдоль кристаллографических осей $a$ или $b$ спектры двух 


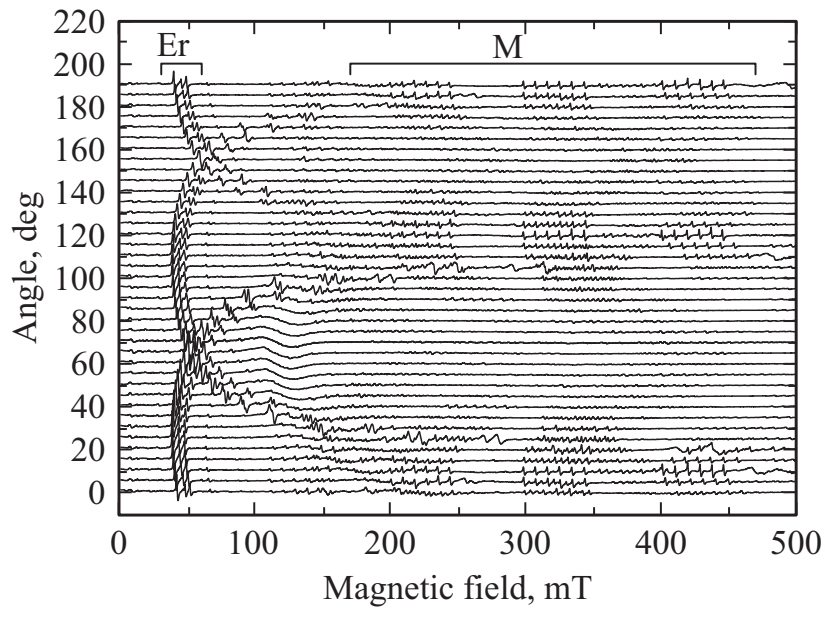

Рис. 1. Спектры ЭПР форстерита, легированного ионами $\mathrm{Er}^{3+}$, записанные при различной ориентации внешнего магнитного поля $\left(B_{0}\right)$ в кристаллографической плоскости $(a b)$. Положение нулевой линии спектров по оси ординат соответствует относительной ориентации $B_{0} \| \quad a$ при $155^{\circ}$.

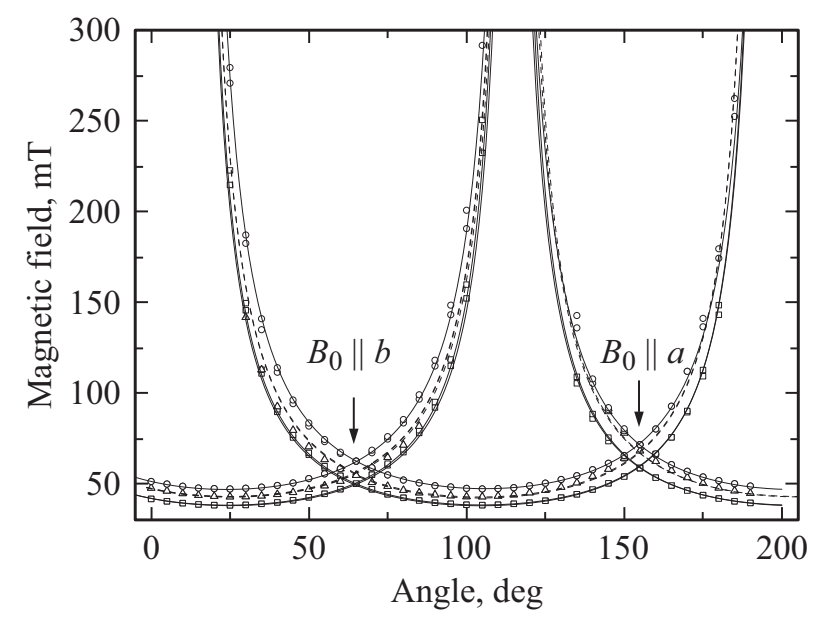

Рис. 2. Зависимости резонансных значений магнитного поля от ориентации магнитного поля относительно кристаллографических осей в плоскости $(a b)$. Кружки и квадраты эксперимент для димерного ассоциата, треугольники - для одиночного иона, линии- расчет.

групп совпадают. Такая ориентационная зависимость характерна для примесного иона, замещающего магний в позиции М1. Спектральные линии (М) принадлежат неидентифицированному нами иону группы железа с величиной ядерного спина $I=5 / 2$.

На рис. 2 приведены ориентационные зависимости положения резонансных линий на этих спектрах. Видно, что при вращении магнитного поля в плоскости $(a b)$ наблюдаются три различных резонансных перехода, для которых резонансные значения магнитного поля равны 59, 65.5 и $71.3 \mathrm{mT}$ при ориентации магнитного поля вдоль оси $b$, и 62.7, 55.0 и $50.4 \mathrm{mT}$ при ориентации магнитного поля вдоль оси $a$. Причем, для всех трех переходов наблюдаются по 4 магнитно неэквивалентных центра, а ориентационные зависимости спектров ЭПР очень близки. Это означает, что все эти резонансные переходы принадлежат ионам эрбия в кристаллографической позиции М1. Ион эрбия в основном состоянии имеет полный электронный магнитный момент $J=15 / 2$ и является крамерсовым ионом, для которого в нулевом магнитном поле электронные штарковские подуровни должны быть, по крайней мере, двукратно вырожденными. Для таких ионов три различных резонансных перехода, соответствующие трем различным резонансным значениям магнитного поля $B_{0}^{i}$, могут соответствовать трем кристаллографически различным центрам эрбия с различными значениями эффективного $g$-фактора

$$
B_{0}^{i}=\frac{v}{\beta g_{\mathrm{eff}}^{i}},
$$

$i=1,2,3$. Здесь $v-$ рабочая частота спектрометра, $g_{\text {eff }}^{i}$ - эффективный $g$-фактор $i$-того резонансного перехода, $\beta$ - магнетон Бора.

В этом случае изменение частотного диапазона записи спектра должно приводить к пропорциональному изменению резонансных магнитных полей, и изменению расщепления между резонансными линиями на спектре ЭПР. Второй возможный вариант - образование димерных ассоциатов, в которые входят два иона эрбия, связанные спин-спиновым взаимодействием. Такой димерный ассоциат имеет один синглетный электронный уровень, для которого суммарный магнитный момент равен нулю, и три триплетных электронных уровня, характеризующихся суммарным магнитным моментом равным 15. Для димерного ассоциата, который является некрамерсовым парамагнитным центром, спин-спиновые взаимодействия приводят к ненулевым расщеплениям $\Delta$ между электронными штарковскими подуровнями в нулевом магнитном поле. В этом случае расщепление между резонансными линиями на спектре ЭПР определяется величиной $\Delta$ и не связано с различиями в величине $g$-фактора.

$$
B_{0}^{i}=\frac{v-\Delta^{i}}{\beta g_{\text {eff }}} .
$$

Для ответа на вопрос о природе появления трех резонансных переходов на спектрах ЭПР иона эрбия в форстерите были проведены измерения спектров ЭПР в Q-диапазоне. На рис. 3, где представлены спектры, записанные в X- и Q-диапазонах, хорошо видно, что при увеличении рабочей частоты спектрометра в три раза расстояние между резонансными линиями на спектрах почти не изменилось. Поэтому можно сделать однозначный вывод о том, что на показанных спектрах одна линия (средняя) принадлежит одиночному иону эрбия, а две крайние - димерному ассоциату. Величины $\Delta^{i}$, полученные аппроксимацией прямыми линиями экспериментальных данных X- и Q-диапазонов равны - 1.323 , -0.068 и $0.704 \mathrm{GHz}$.

На спектрах, приведенных на рис. 3 видно, что резонансные линии одиночного иона и димерного ассоциата 

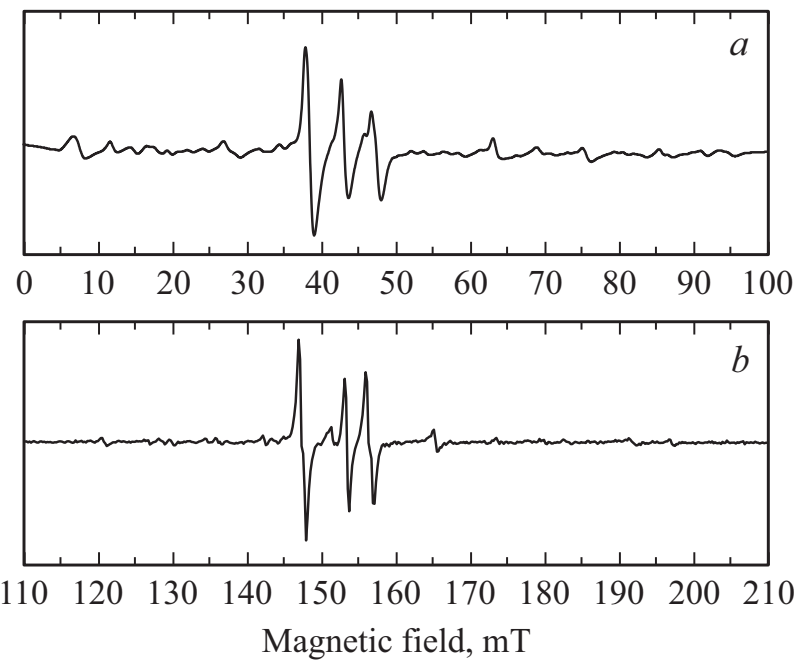

Рис. 3. Спектры ЭПР эрбия в синтетическом форстерите, записанные в различных диапазонах при ориентации магнитного поля, соответствующей минимальным значениям резонансного магнитного поля на рис. $2(110 \mathrm{deg}) . a-\mathrm{X}$-диапазон, частота спектрометра $9.378 \mathrm{GHz}, b-\mathrm{Q}$-диапазон, частота спектрометpa $33.93 \mathrm{GHz}$.

имеют примерно одинаковую интенсивность. Это означает, что концентрации данных парамагнитных центров сопоставимы. При строго статистическом распределении одинаковых примесных ионов по узлам кристаллической решетки отношение концентраций димерных центров $C_{\text {dimer }}$ и одиночных ионов $C_{\text {single }}$ определяется соотношением [11]

$$
C_{\text {dimer }} / C_{\text {single }}=2 c(1-c)^{2},
$$

где $c$ - общая мольная доля примесных ионов в кристалле по отношению к замещаемому ими основному компоненту матрицы. Как уже говорилось, фактическая концентрация эрбия в исследуемом „рабочем“ образце составляет $0.025 \pm 0.001$ at.\% по отношению к магнию. Ясно, что при столь небольших концентрациях ионов эрбия в структуре форстерита вероятность образования димеров, согласно (3) должна быть на несколько порядков ниже, чем вероятность образования одиночных ионов.

Сравнимая интенсивность линий димерного ассоциата и одиночного иона эрбия говорит о том, что соотношение (3) для ионов эрбия в форстерите не выполняется. Иными словами, аналогично случаю с кристаллами форстерита, легированного ионами гольмия $[1,2]$, тербия [4] и иттербия [5] в данном случае налицо сильно выраженная тенденция к димерной самоорганизации примесных ионов эрбия.

Для определения магнитных характеристик эрбия в форстерите были измерены ориентационные зависимости спектров ЭПР при вращении магнитного поля в кристаллографических плоскостях $(a c)$ и $(b c)$. Результаты представлены на рис. 4 и 5. Отметим, что в пер- вом случае регистрировались только линии, обязанные одиночному иону, а во втором - только димерному ассоциату.

Для теоретического описания ориентационных зависимостей спектров ЭПР использовался специализированный пакет программ EasySpin [12,13]. При этом для описания электронной спиновой системы использовался эффективный спин $S=1 / 2$.

Наилучшее совпадение расчетных данных с экспериментом было получено при параметрах парамагнитных центров, приведенных в таблице.

В этой таблице значения углов Эйлера приведены для одного из 4 магнитно-неэквивалентных центров.

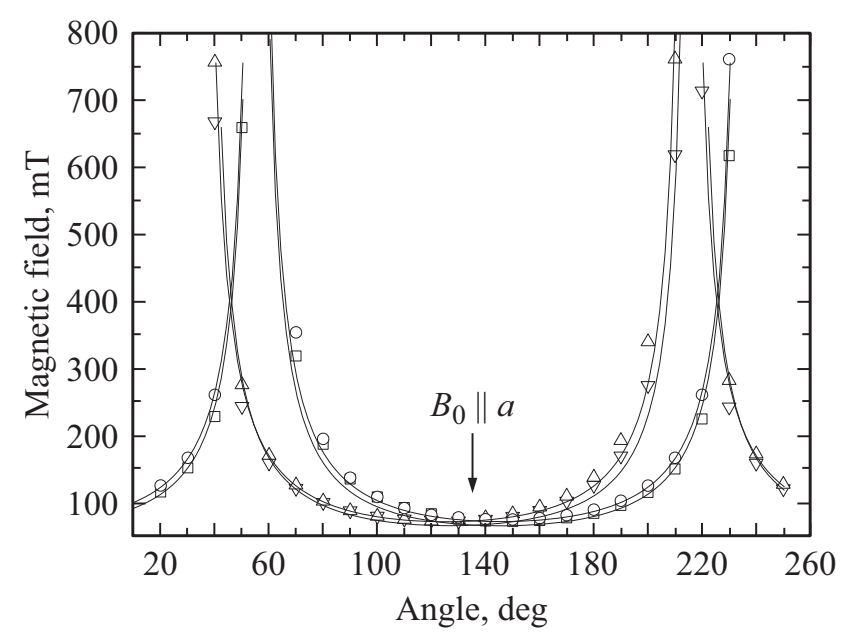

Рис. 4. Ориентационные зависимости положения резонансных линий одиночного иона $\mathrm{Er}^{3+}$ в форстерите на спектрах ЭПР при вращении магнитного поля в плоскости $(a c)$ в Х-диапазоне. Значки - эксперимент, линии - расчет.

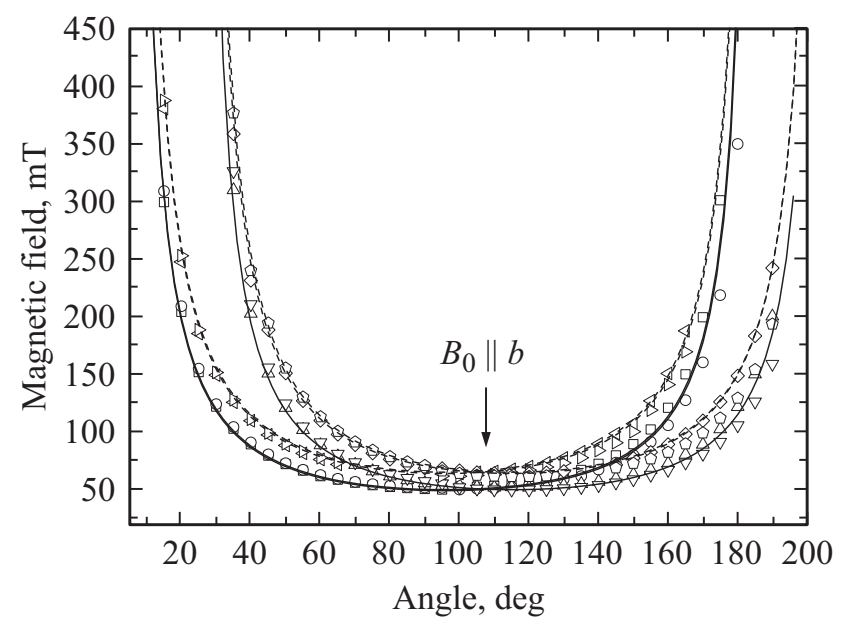

Рис. 5. Ориентационные зависимости положения резонансных линий димерного ассоциата $\mathrm{Er}^{3+}$ в форстерите на спектрах ЭПР при вращении магнитного поля в плоскости $(b c)$ в Х-диапазоне. Значки - эксперимент для четырех магнитно неэквивалентных позиций ионов эрбия, линии - расчет. Сплошные и штриховые линии соответствуют резонансным переходам, расщепленным вследствие спин-спинового взаимодействия. 
Параметры парамагнитных центров, образованных примесными ионами эрбия в форстерите

\begin{tabular}{|c|c|c|c|}
\hline \multicolumn{2}{|l|}{ Параметр } & $\begin{array}{c}\text { Одиночный } \\
\text { ион }\end{array}$ & $\begin{array}{c}\text { Димерный } \\
\text { ассоциат }\end{array}$ \\
\hline Главные значения $g$-тензора & $\begin{array}{l}g_{x} \\
g_{y} \\
g_{z}\end{array}$ & $\begin{array}{c}0 \\
1.2 \\
15.6\end{array}$ & $\begin{array}{c}0 \\
0 \\
15.6\end{array}$ \\
\hline $\begin{array}{l}\text { Углы Эйлера }(\mathrm{deg}) \text { для ориентации главных осей } g \text {-тензора }(x, y, z) \\
\text { относительно кристаллографических осей }(a, b, c) \text {. Вращения } z y z\end{array}$ & $\begin{array}{l}\alpha \\
\beta \\
\gamma\end{array}$ & $\begin{array}{l}-0.3 \\
83.8 \\
52.0\end{array}$ & $\begin{array}{l}-0.93 \\
82.5 \\
49.6\end{array}$ \\
\hline Главные значения тензора спин-спинового $(\mathrm{GHz})$ взаимодействия & $\begin{array}{l}J_{x} \\
J_{y} \\
J_{z} \\
\end{array}$ & & $\begin{array}{r}0 \\
0 \\
-2.78 \\
\end{array}$ \\
\hline $\begin{array}{l}\text { Углы Эйлера }(\mathrm{deg}) \text { для ориентации главных осей тензора спин-спинового } \\
\text { взаимодействия }(x, y, z) \text { относительно кристаллографических осей }(a, b, c) \text {. } \\
\text { Вращения } z y z .\end{array}$ & $\begin{array}{l}\alpha \\
\beta \\
\gamma\end{array}$ & & $\begin{array}{r}2.8 \\
100.8 \\
67.7\end{array}$ \\
\hline
\end{tabular}

Для других центров значения углов Эйлера могут быть получены с использованием свойств симметрии кристаллической решетки форстерита. При этом для одиночного иона и димерного ассоциата главные магнитные оси $z$ четырех магнитно неэквивалентных центров отклонены от плоскости $(a b)$ на углы \pm 6.2 и $\pm 7.5 \mathrm{deg}$ соответственно, а их проекции на плоскость $(a b)$ отклонены от оси а на углы \pm 54 и $\pm 51 \mathrm{deg}$ соответственно. Магнитные свойства всех центров характеризуются сильной анизотропией, близкой к одномерному магнетизму изинговского типа. Небольшие значения поперечных компонент $g$-тензора приводят к тому, что вероятность резонансных переходов при некоторых ориентациях магнитного поля становится очень малой, и не все резонансные переходы регистрируются при ориентации магнитного поля в плоскостях $(a c)$ и $(b c)$.

Мы полагаем, что ионы эрбия в форстерите образуют ассоциаты вида $\left[\mathrm{Er}_{\mathrm{Mg}}^{\bullet}-\mathrm{V}_{\mathrm{Mg}}^{\prime \prime}-\mathrm{Er}_{\mathrm{Mg}}^{\bullet}\right]$, в которых два иона $\mathrm{Er}^{3+}$ располагаются в позициях М1 одной и той же линейной цепочки октаэдров, вытянутой вдоль оси $c$, а вакансия $\mathrm{Mg}^{2+}$ находится в позиции M1 между этими двумя ионами $\mathrm{Er}^{3+}$. При этом ионы $\mathrm{Mg}^{2+}$, замещаемые ионами $\mathrm{Er}^{3+}$, образующими димерный ассоциат, находятся друг от друга на расстоянии $0.6 \mathrm{~nm}$. Это достаточно большое расстояние, что позволяет нам рассматривать характер взаимодействия между ионами $\mathrm{Er}^{3+}$ в димерном ассоциате как чисто магнитно-дипольный. Поскольку величина и ориентация магнитного момента ионов $\mathrm{Er}^{3+}$ в димерном ассоциате нам известны из эксперимента, энергия диполь-дипольного взаимодействия может быть рассчитана по формуле

$$
J=\frac{1}{2} \frac{g_{z}^{2} \mu_{\beta}^{2}}{r^{3}}\left(3 \cos ^{2} \theta-1\right),
$$

где $r$ - расстояние между ионами, $\theta-$ угол между $z$-осью магнитного момента и радиусом-вектором, соединяющим ионы. Энергия диполь-дипольного взаимодействия $J$, рассчитанная по формуле (4), равна $-3.4 \mathrm{GHz}$, что находится в удовлетворительном согласии с полученными экспериментальными данными.

\section{4. Заключение}

Методом стационарной ЭПР-спектроскопии в $\mathrm{X}$ - и Q-диапазонах исследованы монокристаллы синтетического форстерита, легированный ионами эрбия. Установлено, что ионы эрбия замещают ионы магния преимущественно в кристаллографической позиции М1 в виде одиночных ионов и димерных ассоциатов. Определены магнитные характеристики парамагнитных центров, образованных ионами эрбия. Обнаружен эффект димерной самоорганизации примесных ионов эрбия в форстерите, заключающийся в том, что концентрация димерных ассоциатов на несколько порядков превышает концентрацию ассоциатов, образующихся случайно при статистическом распределении примесных ионов в кристаллической решетке.

Авторы выражают признательность В.А. Шустову (КФТИ им. Е.К Завойского) за рентгенографические исследования образцов, Д.А. Николаеву (ИОФ им. Прохорова РАН) за измерение спектров оптического поглощения кристаллов и В.Г. Сенину (ГЕОХИ им. Вернадского РАН) за измерение фактических концентраций эрбия в кристаллах методом рентгеноспектрального микроанализа.

\section{Список литературы}

[1] А.В. Гайстер, Е.В. Жариков, А.А. Коновалов, К.А. Субботин, В.Ф. Тарасов. Письма в ЖЭТФ 77, 753 (2003).

[2] A.A. Konovalov, D.A. Lis, B.Z. Malkin, S.I. Nikitin, K.A. Subbotin, V.F. Tarasov, E.N. Vorobieva, E.V. Zharikov, D.G. Zverev. Appl. Magn. Res. 28, 267 (2005).

[3] A.A. Konovalov, D.A. Lis, K.A. Subbotin, V.F. Tarasov, E.V. Zharikov. Appl. Magn. Res. 30, 673 (2006). 
[4] A.A. Konovalov, D.A. Lis, K.A. Subbotin, V.F. Tarasov, E.V. Zharikov. Appl. Magn. Res. 45, 193 (2014).

[5] В.Ф. Тарасов, А.А. Суханов, В.Б. Дудникова, Е.В. Жариков, Д.А. Лис, К.А. Субботин. Письма в ЖЭТФ 106, 78 (2017).

[6] В.С. Урусов, В.Б. Дудникова, Е.П. Смирнова, И.Н. Аникин, Е.И. Казинская. Геохимия 8, 1199 (1989).

[7] T. Kobayashi, H. Takei. Earth Planet. Sci. 36, 231 (1977).

[8] В.Б. Дудникова, В.С. Урусов, Е.В. Жариков. Неорган. материалы 41, 6, 1 (2005).

[9] Ф. Крегер. Химия несовершенных кристаллов. Мир, М. (1969). $654 \mathrm{c}$

[10] C.A.J. Ammerlaan, I. de Maat-Gersdorf. Appl. Magn. Res. 21, 13 (2001).

[11] M. Motokawa, H. Ohta, N. Makita, H. Ikeda. J. Phys. Soc. Jpn. 61, 322 (1992).

[12] S. Stoll, A. Schweiger. J. Magn. Res. 78, 42 (2006).

[13] S. Stoll, A. Schweiger. Biol. Magn. Res. 27, 299 (2007).

Редактор Т.Н. Василевская 